\title{
Envelhecimento, estratégias de enfrentamento do idoso e repercussões na família
}

\author{
Aging, facing strategies of the aged and the consequences for family \\ Envejecimiento, estrategias de afrontamiento de los ancianos y impactos en la familia
}

\section{Ana Lúcia de Moraes Horta', Denise Cristina de Oliveira Ferreira', Li Men Zhao'}

'Universidade Federal de São Paulo. Escola Paulista de Enfermagem. São Paulo, SP

Submissão: 12/12/2008

Aprovação: 05/06/2010

\section{RESUMO}

Trata-se de estudo Qualitativo para conhecer a percepção de idosos, usuários de Unidade Básica de Saúde de São Paulo, sobre envelhecimento, estratégias de enfrentamento e repercussões na família. Foram realizadas, de setembro de 2007 a julho de 2008 , entrevistas com três idosos, de $7 \mathrm{I}$ a 90 anos. Os participantes responderam às perguntas da Escala de Depressão Geriátrica, Ecomapa, Genograma e modelo Calgary. Com análise de conteúdo de Bardin, encontramos três categorias - percebendo o momento do ciclo vital; sofrendo as repercussões deste momento; enfrentando o envelhecimento e a velhice. Acreditamos na continuidade de estudos Que busquem estratégias com idosos e famílias na tentativa de melhorar a Qualidade de vida e dinâmica familiar com inclusão de entretenimento, segundo possibilidade da comunidade.

Descritores: Saúde da família; Idoso; Atenção primária à saúde.

\section{ABSTRACT}

This Qualitative study seeks the understanding of the perception of the elderly, users of Basic Health Unit of São Paulo, on aging, coping strategies and impact on family. Interviews with three elderly people, from 71 to 90 years-old, were held from September 2007 to July'2008. Participants responded to Questions under the Geriatric Depression Scale, Ecomapa, Genogram and Calgary model. From the Bardin analysis, we could determine three categories - the moment of realizing the life cycle; suffering the consequences of this time; facing the aging and old age. We believe in the continuity of studies that search for strategies with older people and their families in an attempt to improve life Quality and family dynamics by the inclusion of entertainment, according to the possibilities offered to their communities.

Key words: Family health; Elderly; Primary health care.

\section{RESUMEN}

El siguiente estudio cualitativo busca comprender la percepción de las personas de edad avanzada, usuarios de la Unidad Básica de Salud de São Paulo, en cuanto al envejecimiento, estrategias de afrontamiento y el impacto en la familia. Se hicieron entrevistas desde Septiembre del 2007 hacia Julio del 2008 con tres personas mayores, de los 71 a 90 años. Los participantes contestaron a las preguntas de la Escala de Depresión Geriátrica, Ecomapa, Genograma y modelo Calgary. A través del análisis de Bardin, hemos descubierto tres categorías - el momento de darse cuenta del ciclo de la vida; se sufren las consecuencias de ese momento; se enfrentan el proceso de envejecimiento y la vejez. Creemos en la continuidad de los estudios que buscan estrategias con las personas mayores y sus familias para mejorar la calidad de vida y la dinámica familiar a través de la inclusión del entretenimiento, acuerdo a las posibilidades ofrecidas a la comunidad.

Descriptores: Salud de la familia; Ancianos; Atención primaria de la salud.

*Pesquisa financiada pelo Programa de Bolsas de Extensão PIBEX 2007/2008 da Universidade Federal de São Paulo.

AUTOR CORRESPONDENTE Ana Lúcia de Moraes Horta. Rua Tutoia, 815 - apto 72. Vila Mariana. CEP 04007-005. São Paulo, SP.

E-mail: eryana.ops@terra.com.br 


\section{INTRODUÇÃO}

Estima-se Que, para o ano de 2050, existirão dois bilhões de pessoas com 60 anos e mais em todo o mundo ${ }^{(1)}$. No Brasil, a população envelhece em igual velocidade, sendo Que a cada ano são incoporados à população brasileira 650 mil idosos $^{(2)}$.

Considerando a dimensão da saúde, a população idosa brasileira é acometida por diversas afecções crônicas que demandam cuidados integrais e atendimento de saúde constante, com comprometimento da eualidade de vida.

Um dos agravos à saúde com grande potencial de incapacitar o indivíduo, principalmente na população idosa, é a depressão. Estimase Que em 2020 a depressão será a segunda causa específica de incapacitação nos países desenvolvidos e a primeira causa nos países em desenvolvimento ${ }^{(1)}$.

Este transtorno psiQuiátrico é muito comum entre idosos. Alguns estudos revelam Que sintomas depressivos ocorrem em 14,7\% dos idosos vivendo em comunidade ${ }^{(3)}$. No Brasil, a prevalência de depressão entre as pessoas idosas varia de $4,7 \%$ a $36,8 \%$. É uma doença potencialmente fatal, pois pessoas idosas apresentam risco de suicídio maior do que pessoas jovens ${ }^{(1)}$.

A depressão é uma morbidade de difícil mensuração, pois seu Quadro clínico, muitas vezes, possui apresentações atípicas e peculiaridades como predominância de sintomas somáticos, irritabilidade e dificuldades cognitivas, Que podem dificultar o diagnóstico e o tratamento desse transtorno de humor ${ }^{(4)}$.

Em virtude da sua relevância, considera-se a depressão um grave problema de saúde pública, na medida em Que provoca tanto incapacidade individual Quanto sérios problemas familiares.

Nas famílias, enQuanto os indivíduos envelhecem, vão ocorrendo mudanças na organização familiar em termos de papéis dos membros e de suas regras, estagiando as famílias em ciclos vitais. Esta fase de realinhamento dos papéis familiares pode ser acompanhada de certa dificuldade de adaptação não só por parte do idoso, mas também pelos demais familiares Que passam a cuidar dele $e^{(5)}$.

Todas essas alterações são de difícil aceitação pelo indivíduo idoso e se tornam mais um agravante ao seu estado de saúde mental. Diante dessa problemática e considerando a influência dessa crise na dinâmica familiar, realizamos esta pesquisa na tentativa de compreender este momento do ciclo de vida familiar.

\section{OBJETIVO}

Conhecer a percepção de idosos sobre envelhecimento, estratégias de enfrentamento e repercussões na família de usuários de Unidade Básica de Saúde em município de São Paulo.

\section{METODOLOGIA}

Trata-se de um estudo Qualitativo. A pesquisa foi desenvolvida no período de setembro de 2007 a julho de 2008, com idosos usuários de uma Unidade Básica de Saúde na Zona Norte de São Paulo.

A pesquisa foi protocolada na base de dados do SINESP (Sistema Nacional de Ética em Pesquisa) e aprovada pelo Comitê de Ética em Pesquisa da Secretaria Municipal de Saúde de São Paulo (SMS/
SP) pelo $n^{\circ} 119 / 08$. Os sujeitos assinaram o termo de consentimento livre e esclarecido.

Os participantes foram incluídos a partir de visitas domiciliárias às famílias Que tinham pelo menos um integrante idoso com suspeita de depressão e com grau de cognição suficiente para manter diálogo compreensível, segundo avaliação da equipe do PSF. Os idosos depressivos foram identificados pela Escala de Depressão Geriátrica (EDG) de Yesavage, versão simplificada com 15 perguntas $^{(6)}$.

Esta escala atribui pontuação às respostas dos sujeitos, classificando-os em "sem depressão" (com 0 a 4 pontos), "depressão leve ou moderada" (com 5 a 10 pontos) e "depressão grave ou severa" (de 11 a 15 pontos).

Após a aplicação da escala, os idosos foram entrevistados em sessão única, de aproximadamente uma hora, seguindo a seguinte Questão norteadora: "Como o(a) sr(a) tem se sentido emocionalmente na última semana?". A entrevista gravada foi guiada por um roteiro temático Que compreende Questões sobre o estado de humor atual do idoso, sua saúde, suas relações familiares e redes de apoio.

Para conhecer as redes de apoio foi construído um Ecomapa e Genograma, baseando-se no método Calgary de avaliação familiar ${ }^{(7)}$, para facilitar o entendimento da estrutura e dinâmica familiar na tentativa de compreender a repercussão e formas de enfrentamento nesse momento do ciclo vital familiar.

As informações gravadas nas entrevistas foram transcritas integralmente. Realizamos a análise de conteúdo dos discursos dos participantes segundo modelo de Bardin ${ }^{(8)}$.

\section{RESULTADOS E DISCUSSÃO}

Foram entrevistados três idosos, sendo um homem de 71 anos, uma mulher de 78 anos e outra de 90 anos. As duas idosas entrevistadas apresentaram escore 12 na EDG, caracterizando depressão grave, enQuanto Que o idoso não apresentou depressão segundo a escala (escore 3 ).

Durante a análise das entrevistas, identificamos três grandes temas Que permearam as falas dos participantes, os Quais serão neste texto apresentados como três principais categorias: Percebendo o momento do ciclo vital; Sofrendo as repercussões deste momento; e Enfrentando o envelhecimento e a velhice.

\section{Percebendo o momento do ciclo vital}

Os sujeitos ouvidos se consideram doentes, valorizam mais as perdas do Que os ganhos, mantêm autonomia porém com certo grau de dependência, não gostam de socialização, não desenvolvem atividades coletivas, são religiosos, têm medo da morte e idealizam a longevidade.

A atual linha de raciocínio gerontológico não concebe mais o envelhecer como uma experiência homogênea, são várias as modalidades de envelhecimento e as concepções de velhices. ${ }^{(9)}$

Podemos perceber que as alterações na saúde decorrentes do envelhecimento parecem ser a causa da diminuição do "bom humor" relatada pelo participante. Os problemas de saúde da própria pessoa ou de pessoas próximas são apontados como eventos estressantes por mais da metade dos idosos ${ }^{(10)}$.

[...] Quando eu tinha saúde eu tinha um bom humor, agora que 
não tem saúde mais acabou [...] (P3)

Uma característica relacionada ao envelhecimento, citada pelos sujeitos, é a aposentadoria. Todos eles trabalhavam e tiveram de parar suas atividades laborais.

[...] chega nos 60 anos não ta aguentando mais aí tem Que aposentar[...] Não posso trabalhar, por causa da idade ninguém Quer. (PI)

A perda da posição social após a aposentadoria leva o idoso a interromper suas responsabilidades relacionadas ao mundo do trabalho e da produção, gerando rótulo de inútil e improdutivo. Se não houver um planejamento prévio, o desvinculamento com o trabalho torna-se traumático, envolvendo a perda da auto-identidade e levando a alguns distúrbios psicológicos e depressão(II).

Durante o processo de envelhecimento, as famílias envelhecem juntamente com seus membros e sofrem mudanças na sua constituição. Um participante convivia com sua esposa, uma idosa morava com sua irmã e outra vivia sozinha. As mulheres das famílias desempenham papel de cuidadoras dos entrevistados, o Que demonstra coerência com resultados de diversos estudos relativos à influência do gênero no cuidado. Além disso, as cuidadoras dos participantes também são idosas, situação comum no cenário familiar brasileiro ${ }^{(12)}$.

Percebemos Que as famílias estão se tornando cada vez menores, e a deficiência de relações pode resultar em um sentimento de solidão.

[...]Fazer comida pra gente sozinha é chato nél ...] ficar sozinha é ruim $[\ldots]$ (P3)

No entanto, para esta idosa, a solidão é contraposta à conQuista da liberdade adeuirida com o envelhecimento e com a saída dos filhos de casa. É possível que os benefícios desta escolha sejam superiores aos prejuízos, como vemos na fala seguinte:

[...] a gente tem que guardar a liberdade da gente né [...] Eu acho a Que é bom cada um na sua casa. (P3)

\section{Sofrendo as repercussões deste momento}

Nessa fase da vida o idoso tem Que conviver com perdas físicas resultantes do desgaste biológico e da maior propensão às morbidades, tanto agudas Quanto crônicas ${ }^{(13)}$. Os entrevistados ressaltam as mudanças biológicas resultantes do desgaste físico, do declínio da força muscular, redução da disposição e fadiga característicos da velhice:

\section{[...] cansaço, não dá coragem de fazer nada|...] (PI);}

\section{[...J Tenho dificuldade de andar[...] (P2).}

Ao mesmo tempo, essas limitações naturais se entrelaçam e se confundem com processos patológicos Que comprometem a saúde dos entrevistados.

[...] Estômago, perna, vista, um monte de coisa [...] A pressão é altal...] (PI)

\section{[...] todo dia me dói uma coisa. (P3)}

Com a saúde comprometida os idosos podem apresentar dificuldades para executar atividades antes exercidas normalmente, gerando alterações da rotina, o Que impede a realização de atividades prazerosas e extra-familiares:

[...] Eu andava de ônibus[...] passeava [...] mas agora não vou mais [...] Não posso nem ir na venda com minha esposa, porQue dói demais $[. .].(\mathrm{P} 2)$

Estas mudanças de atividades geram frustrações e sentimento de vergonha e impotência:

\section{[...] Não gosto de falar[...] por causa dos dentes [...] (PI)}

[...] eu não tenho preguiça, eu tenho vontade de fazer, é Que não dá né [...]O pior é isso, eu Quero fazer mas não posso [...] (PI)

A sensação de impotência é acompanhada da necessidade de auxílio de outras pessoas para suas necessidades básicas. Desta forma a dependência se torna uma repercussão do envelhecimento.

A dependência não é um estado permanente, é um processo dinâmico cuja evolução pode se modificar e até ser prevenida ou reduzida se houver ambiente e assistência adequados ${ }^{(14)}$.

\section{Enfrentando o envelhecimento e a velhice}

Nos idosos há expressiva variabilidade nas formas de enfrentamento, uma vez Que estão expostos a diferentes circunstâncias sociais e pessoais, atuais e passadas, além de possuírem diferentes formas de interpretar e lidar com eventos estressantes $^{(10)}$.

As estratégias de enfrentamento estão entre os mecanismos de auto-regulação do self Que intervêm na adaptação e a determinação de bem-estar subjetivo ao longo de toda a vida e também na velhice. Concordamos Que os mecanismos de enfrentamento podem funcionar como elementos amortecedores dos efeitos de eventos estressantes $^{(15)}$.

Em estudo(10), pesquisadores classificaram os eventos estressantes relacionados à finitude, problemas com os descendentes, ao cuidado, ao bem-estar psicológico e eventos pontuais de crise. lá os fatores das estratégias de enfrentamento podem ser (a) Fator com foco na expressão de emoções negativas, em excessos comportamentais e em comportamentos de risco; (b) Fator com foco em tentativas de controle sobre o ambiente; (c) Fator com foco na religiosidade como elemento amortecedor; (d) Fator com foco na atenuação do potencial estressor do evento, mediante comportamentos de esquiva; (e) Fator com foco em inibição das emoções, tendência à não-expressão emocional aberta e ao recolhimento ao mundo interno.

Em analogia aos resultados desta peseuisa citada, as estratégias de enfrentamento utilizadas pelos nossos participantes foram enfocadas nos fatores (c), (d) e (e).

A estratégia comum aos três participantes é com foco na espiritualidade, na Qual reza, pede orientação, acredita na vontade de Deus e delega a responsabilidade de superar o problema a um 
ser superior, como podemos observar nas seguintes frases:

[...] eu rezo tanto pra melhorar para poder fazer as coisa [...] (PI)

[...] eu falo com Ele toda noite...até agora tem me atendido [...] (P2)

\section{[...] eu tenho Que me conformar com o Que Deus Quer né? (P3)}

A espiritualidade pode ter uma dimensão central na vida dos idosos relacionada ao surgimento, à manutenção e às possibilidades de atenuação de agravos à saúde física e mental ${ }^{(16)}$. A busca da espiritualidade com o avançar da idade é fonte importante de suporte emocional. Práticas e crenças religiosas parecem contribuir decisivamente para o bem-estar na velhice, sobretudo pelo apoio social e pelos modos de lidar com o estresse ${ }^{(17)}$.

A fé constitui um modo de pensar construtivo, é um sentimento de confiança de Que acontecerá o Que se deseja. As pessoas se nutrem muitas vezes da sua fé, portanto, as ações de saúde dirigidas aos idosos precisam incluir reforços para manter e/ou desenvolver a espiritualidade, independente de QualQuer credo ou convicção religiosa. A fé em Deus é um sentimento arraigado na nossa cultura e é tão necessária Quanto são outros modos de enfrentamento ${ }^{(18)}$.

O profissional de saúde tem dificuldade em diferenciar a presença de sintomas depressivos da personalidade normal do sujeito. Sabemos que a velhice não muda a estrutura da personalidade dos indivíduos, apenas pode acentuar certos traços ou tendências ${ }^{(19)}$. Assim uma pessoa Que, durante a juventude, possui características introspectivas tende a envelhecer mantendo esses mesmo traços, os Quais, aos olhos dos outros, podem parecer sinal de alteração psicológica. Desta forma, nem todo indivíduo Que se isola do seu círculo social está deprimido.

\section{[...] eu fico Quieto, não é depressão". (P2)}

Outra forma de enfrentamento das situações estressantes ou problemas são atitudes de conformismo ou negação, como podemos perceber nas seguintes frases:

[...] não dá vontade de fazer nada. Dá um desânimo total... Deu um completo bloqueio na minha vida(...)” (P2)

\section{[...] eu fico aqui sentado tentando descobrir alguma coisa pra} fazer essa operação". (P2)

[...] eu sou muito calma....tem muita coisa Que eu vejo errado... mas não falo nada ... não reclamo". (PI)

A razão para esse tipo de enfrentamento talvez possa ser esclarecida pela falsa crença de Que a velhice é sinônimo de doenças, de incapacidades, de dependências funcionais, e portanto, de conformação da situação no Qual se encontra e da negação da habilidade de superar as adversidades. A falta de auto-confiança é um grande fator produtor de alterações negativas no humor, percebidas como desânimo ou falta de interesse pela vida ${ }^{(18)}$.

O idoso pronuncia a palavra "morte" sugerindo uma concepção comum de Que a velhice é a antecâmara da morte ${ }^{(20)}$, momento do ciclo vital em Que não há mais perspectiva de futuro.

\section{[...] esperar alguma coisa....A morte". (P2)}

Neste momento da entrevista, houve a intervenção da esposa do entrevistado, também idosa, a Qual descordou do marido e afirmou não esperar a morte tão cedo e pretende viver mais 20 anos. Seguindo o mesmo raciocínio, o entrevistado em seguida rebate, contradizendo sua fala anterior:

\section{[...] também espero viver mais trinta... Chegar aos 100 [...] (P2)}

Podemos compreender deste diálogo o Quão forte é o tabu da morte na nossa sociedade, pois é muito difícil falar nesse assunto, e mesmo que essa seja a única certeza que a humanidade tem - a de Que vamos todos morrer um dia - ainda assim não estamos preparados para sua chegada, sonhamos com uma vida longa e desejamos postergar esse evento inevitável.

O envelhecimento humano se processa pela ação do tempo sobre os indivíduos. Tempo individual da vida de cada um, Que se esgota na finitude objetivada na morte biológica. Envelhecer e morrer são experiências vitais singulares, próprias de cada ser, contudo, são reguladas por padrões socioculturais Que definem a significação de cada uma dessas experiências humanas, na especificidade de uma época e um lugar da história da humanidade.

A finitude é atualmente negada pela cultura do consumo, a mesma cultura Que, paradoxalmente, a evidencia na mídia, mostrando as mortes múltiplas na brutalidade da violência urbana e nos mega-ataques internacionais ${ }^{(21)}$.

A pertinência do tema finitude no contexto do envelhecimento evidencia-se, na prática profissional, Quando a atenção ao idoso ao fim da vida viabiliza a práxis paliativa. Portanto, ao entender envelhecimento e finitude, devemos considerar a finalidade do envelhecer um projeto de liberdade individual, afirmado no apoio coletivo. E Que a morte dos seres idosos possa acontecer na dignidade da celebração da vida ${ }^{(21)}$.

Outro aspecto que merece destaque é a participação da rede social aQui vista como a família e os amigos Que compõem a primeira fonte de cuidados, seja de uma forma natural ou imposta. A família predomina como alternativa no sistema de suporte informal aos idosos $^{(14)}$. O suporte social por meio do uso de equipamentos comunitários, redes sociais e relações íntimas, permitem satisfazer necessidades (instrumentais e expressivas) em situações cotidianas e de crise $^{(22)}$.

Há um forte comprometimento da Qualidade de vida dos idosos frente às restrições identificadas e aos poucos recursos institucionais, comunitários e familiares Que dispõem para trabalhar com as dependências individuais identificadas ${ }^{(23)}$.

Com a utilização do Ecomapa, Genograma e método Calgary neste estudo, podemos identificar a estrutura e dinâmica familiar e seus recursos, como as redes de apoio, as formas de comunicação e estratégias de enfrentamento de problemas ou crises. Assim, podemos observar, Quanto à estrutura interna das famílias, são compostas por casais de idosos ou somente o idoso morando sozinho, tendo como cuidadores os próprios membros da família, principalmente a esposa ou irmã. Os três casos apresentam vínculo 
com a família extensa, composta por filhos, netos e amigos, Que os fornecem apoio financeiro e emocional.

São famílias católicas, pertencentes a classes sociais baixas a médias, com dificuldades financeiras e Questões de adição a álcool. Apresentam-se no estágio tardio de vida ${ }^{(7)}$, onde não há convivência de várias gerações, com um caso de retorno da filha para casa após separação conjugal. Apesar da expectativa de inversão do papel de cuidador ser assumido pela filha, o Que ocorre em uma família é a manutenção do cuidado prestado pela esposa idosa, sem participação direta da filha.

Em outra família, não há a necessidade de cuidado ser assumido por alguém, pois a idosa é independente. Já em outro caso, o cuidado é assumido pela irmã, Que também é idosa. Percebemos Que a tarefa de cuidar do idoso com doença crônica é designada ao familiar mais próximo, o eual costuma ser a esposa ou filha, sendo concebido como legado familiar, valor cultural, ou Questão de disponibilidade de Quem está mais próximo.

São comuns problemas de saúde e limitações físicas e funcionais, dependência para realização de atividades de vida diária, e dificuldade de acesso aos serviços públicos de saúde. Diante das alterações biopsicossociais trazidas pelo envelhecimento, as famílias enfrentam os momentos de crise, principalmente, pela busca acentuada da espiritualidade e religiosidade.

É fundamental o conhecimento da equipe de saúde sobre o processo de senescência e senilidade, sobre o contexto familiar e social do idoso, respeitando suas limitações e enfatizando seu potencial remanescente e sua capacidade para o autocuidado.

Concordamos com iniciativas Que promovam saúde integral, bem-estar e Qualidade de vida estarão contribuindo para transformar a velhice numa Questão social e não necessariamente num problema social, podendo ser uma fase da vida a ser desfrutada ${ }^{(9)}$.

\section{CONSIDERAÇÕES FINAIS}

Enfatizamos a importância da continuidade da pesQuisa, ampliando o conhecimento sobre essa fase do ciclo de vida familiar, além de estudos Que promovam ações onde o foco do cuidado não seja somente o idoso, já Que há repercussões na família. É importante Que os serviços de saúde busquem estratégias para incluir as famílias no processo de ciclo vital envolvendo o envelhecimento, não apenas com foco no idoso, mas ampliando a visão para as demandas dos familiares, considerando sua estrutura, dinâmica expectativas e necessidades.

As famílias dos idosos necessitam de atenção e não apenas ser colocadas como cuidadoras, já Que esta fase pressupõe um evento não somente para o idoso mas para todos Que participam desse processo, independente da aproximação, vínculo ou atividade desenvolvida. É uma etapa Que resulta numa inversão dos papéis de cuidado, além de relembrar Que todos nós envelhecemos e a finitude é um fato real da vida.

A limitação do estudo foi a dificuldade de entrevistar outros membros da família Que participam do sistema para poder ampliar a visão sobre o momento vivido, partindo do pressuposto Que cada pessoa envolvida trará contribuição para a compreensão da repercussão e novas estratégias de enfrentamento poderão surgir. É por este motivo Que acreditamos Que outros estudos devem ser realizados buscando possibilidades de inclusão de maior numero possível de integrantes nas entrevistas, além de desenvolver instrumentos possíveis de trabalho onde a família do idoso seja integrada no cuidado, sendo também vista.

\section{REFERÊNCIAS}

I. Ministério da Saúde (BR). Secretaria de Atenção à Saúde. Departamento de Atenção Básica. Envelhecimento e saúde da pessoa idosa. Brasília: Ministério da Saúde; 2006.

2. Brasil. Portaria no 2.528 de 19 de outubro de 2006. Aprova a Política Nacional de Saúde da Pessoa Idosa. Diário Oficial da União 2006 out 26; 1: 142-5.

3. Oliveira DAAP, Gomes L, Oliveira RF. Prevalência de depressão em idosos Que freqüentam centros de convivência. Rev Saúde Pública 2006; 40(4): 734-736.

4. Gazalle FK, Lima MS, Tavares BF, Hallal PC. Sintomas depressivos e fatores associados em população idosa no sul do Brasil. Rev Saúde Pública 2004; 38(3): 365-37I.

5. Angelo M. O contexto familiar. In: Duarte YAO, Diogo MJD. Atendimento domiciliar: um enfoque gerontológico. São Paulo: Atheneu; 2000. p27-31.

6. Padarela EMP, Lourenço RA, Vera RP. Validação da escala de depressão geriátrica em um ambulatório geral. Rev Saúde Pública 2005; 39(6): 918-23.

7. Wright LM, Leahey M. Enfermeiras e famílias: um guia para avaliação e intervenção na família. São Paulo: Rocca; 2002.

8. Bardin L. Análise de conteúdo. $3^{\mathrm{a}}$ ed. Lisboa: Edições 70; 1977.

9. Kertzman OF, Trench BV. Vivendo a idade: reflexões sobre a experiência de envelhecimento. Rev. Kairós 2005 dez; 8(2): 207-219.

10. Fortes-Burgos ACG, Néri AL, Cupertino APFB. Eventos estressantes, estratégias de enfrentamento, auto-eficácia e sintomas depressivos entre idosos residentes na comunidade. Psicol Reflex Crit 2008; 2 I (1): 74-82.

1 I. Beger MLM, Derntl AM. Aposentados e livres... mas para Quê? Os trabalhadores e a representação social da aposentadoria e do projeto de vida pessoal. Rev Kairós 2005; 8(2): 22 I -34.

12. Thober E, Creutzberg M, Viegas K. Nível de dependência de idosos e cuidados no âmbito domiciliar. Rev Bras Enferm 2005; 58(4): 438-43.

13. Murillo EN, Correa MPC, Aguirre OLC. Representaciones de la vejez em relación con el proceso salud-enfermidad de un grupo de ancianos. Hacia Promoción Salud 2006; 1 1:107-18.

14. Caldas CP. Envelhecimento com dependência: responsabilidades e demandas da família. Cad Saúde Pública 2003; 19(3): 773 81 .

15. Neri AL, Fortes ACG. A dinâmica do estresse e enfrentamento na velhice e sua expressão no prestar cuidados a idosos no contexto da família. In: Freitas EV. Tratado de geriatria e gerontologia. $2^{\text {a }}$ ed. Rio de Janeiro: Guanabara-Koogan; 2006. p. 1277-88

16. Floriano PJ, Dalgalarrondo P. Saúde Mental, Qualidade de vida e religião em idosos de um Programa de Saúde da Família. I Bras PsiQuiatr 2007; 56(3): 162-70. 
17. Krause N. Religious meaning and subjective well-being in later life. I Gerontol: Social Sciences 2003; 58B (3): SI60-SI 70.

18. Trentini M, Silva SH, Valle ML, Hammerschmidt KSA. Enfrentamento de situações adversas e favoráveis por pessoas idosas em condições crônicas de saúde. Rev Latino-am Enfermagem 2005; 13(1): 38-45.

19. Souza RF, Skubs T, Brêtas ACP. Envelhecimento e família: uma nova perspectiva para o cuidado de enfermagem. Rev Bras Enferm 2007; 60(3): 263-7.

20. Kovács MJ. As tramas do tempo: perdas e luto no ciclo vital. Rev Kairós 2005; 8(1): 113-22.
21. Py L, Trein F. Finitude e infinitude: dimensões do tempo na experiência do envelhecimento. In: Freitas EV, organizadores. Tratado de geriatria e gerontologia. Rio de Janeiro: GuanabaraKoogan; 2006. p. 1353-60.

22. Guedea MTD, Albuquerque FIB, Tróccoli BT, Noriega JAV, Seabra MAB, Guedea RLD. Relação de bem-estar subjetivo, estratégias de enfrentamento e apoio social em idosos. Psicol Reflex Crítica 2006; 19(2): 301-8.

23. Silva M], Lopes MVO, Araújo MFM, Moraes GLA. Avaliação do grau de dependência nas atividades de vida diária em idosos da cidade de Fortaleza - Ceará. Acta Paul Enferm 2006; I9(2): 20I-6. 